\title{
The Optimal Strategy During Bath
}

\author{
LianHao Sun \\ North China Electric Power University (Baoding)
}

Key Words: Save Water, Temperature, Energy Conservation, Heat Loss

\begin{abstract}
The bathtub water will get cooler during washing because of the heat loss, so we have to add the hot water to make up the loss and reheat the water. However, the bathtub capacity is limited, so the water will overflow when exceeding the capacity. In order to solve this problem, we developed a model of the bathtub temperature in space and time to determine the optimal strategy which can keep temperature without wasting too much water. Then, we determine the extent to the relevant factors our strategy depends upon.

At the beginning, we should develop the model according to the law of energy conservation. First, we calculate the whole heat loss which concludes the heat flow caused by the radiation, on the water surface, and in the cycle of water-bathtub-air. In this step, we use the enthalpy difference formula, heat radiation formula and the Fourier Heat Conduction Law. Second, according to $Q=$ $c m \Delta t$, one can get the numerical solutions of the temperature change with the time by the difference equation.The equation of the temperature and the time can be obtained by fitting these solutions. Third, after discreting the space heat conduction equation, one can get the numerical solution of the space temperature field of the bathtub.

Then, we study the relationship between each two of water supply, the bathtub temperature, the water temperature, the bathtub shape and heat loss on the surface. With the law of the energy conservation, we get the standard between the bath water and the faucet water and make a table for the users (Table 6). We can get the optimal strategy by analyzing the bathtub shape with the method of optimizing the single factor. The optimal one is the circle-bottom athtub. The conclusion has been gotten: the bubble bath additive will reduce the heat loss by reduce the evaporation coefficient and the person's motion will increase the heat loss by speed up the water movement.

In the end, this problem had been solved well by our model which can help us to judge the hot water flow based on our own choice with the model's rationality, intuitive, accuracy and universality.
\end{abstract}

\section{Introduction}

\subsection{Overview and Our Work}

Everyone wants to take a comfortable bath after a whole day's exertion, but there always are some sorry things in our life, for example, the person in the problem just meets the sorry thing that the water may become cooler soon. As we all know, there are some kinds of thermostatic baths now. However, not all of us can afford it and we just have the common one which is just a simple water containment vessel. If we want to reheat the bathing water, we have to add a constant trickle of hot water from the faucet. This brings unnecessary trouble. Besides, with the addition of the hot water, it may overflow if exceed the bath capacity. This will result in waste of water.

So, we should develop a model of the bathtub water temperature in space and time, according to which can determine the best strategy the person in the bathtub can adopt to keep the temperature even throughout the bathtub and as close as possible to the initial temperature without wasting too much water.

The shape/volume of the tub, as well as the shape/volume/temperature of the person, even the motions made by the users, all these factors may affect the temperature in a certain extent. We should determine the extend to which our strategy depend upon those factors by our model. Besides, if someone use a bubble bath additive while initially filling bathtub to assist in cleaning, the result 
will change and we should determine hoe it affect our model's result.

\subsection{Problem Analysis}

The bathtub water temperature drops mainly due to the thermal loss. Therefore, we have to find a way to make up the loss if we want to keep the temperature.

\subsubsection{Thermal Loss}

What causes the thermal loss mainly are the thermal convection happens among the water, the tub wall, body surface and the air, the thermal conduction caused inside the water or the tub wall, the evaporation of the water, the radiation between the water and the bathroom wall and some other factors.

\section{The thermal convection:}

It happens in the cycle of water-bathtub-air, so we just need to calculate these three kinds of the thermal loss between every two of them.

(1)It occurs between the bathtub wall and the water and depend upon the bathtub material, the temperature difference and the contact area. At the beginning, we can chose the common bathtub to develop a basic model. After completing that, we can optimize our model by changing the factors.

(2)It occurs between the bathtub wall and the air, just like the water and the tub wall.

(3)It occurs between the water and the air,and depend upon the temperature difference and the convective heat transfer coefficient which can be checked out in the literature.

(4)It occurs between the body surface and the water whose temperature are almost the same. So we can regard this thermal is zero.

\section{The thermal conduction:}

It occurs in the water inside caused by the water's motion and the inside tub wall. Both of them are depend upon the thermal conductivity which can be checked out in the literature also.

The water's motion depend upon the person, so we should take t into consideration.

\section{The evaporation of the water:}

It can be calculated by the formula.

\section{The radiation:}

It can be calculated by the formula like the evaporation of the water.

\section{Other factors:}

It is the bubble bath additive, it can form a space layer between the water surface and the air, so it may reduce the thermal loss caused by the evaporation.

\subsubsection{Thermal Supply}

The most convenient way is to add hot water. But the method mentioned in the problem is not acceptable because it will water water and can't keep the temperature. To keep temperature, we have to adopt the method adding constant water. So we can add constant but slow flow of the hot water which can keep temperature and save the water.

The thermal supply must equals the thermal loss, so we should develop a model in time to ensure that.

\section{Simplifying Assumptions}

Assume the thermal lost during descent from the introduction of the hot water can be ignored.

Assume the bath water is consistent with over all.

Assume the temperature can not change the water density.

Assume the heat can spread in a short time which can be ignored after the addition of the hot water. 


\section{Main Symbol Description}

\begin{tabular}{ll} 
& Table 1, Main Symbol Description \\
\hline $\mathrm{a}, \mathrm{b}, \mathrm{H}$ & The bathtub inner wall's length, width, height \\
$\mathrm{S}$ & The area \\
$\mathrm{M}$ & The bathtub thickness \\
$\mathrm{Pa}$ & Indoor atmospheric pressure \\
$\mathrm{Q}$ & The heat flow \\
$\Delta t$ & Temperature difference \\
$\mathrm{T}, \theta$ & Water temperature, air temperature \\
$\mathrm{W}$ & Bathroom indoor wind speed \\
$\mathrm{h}, \mathrm{h}_{\theta}$ & Water enthalpy at $\mathrm{t}^{\circ} \mathrm{C}$, air enthalpy at $\theta^{\circ} \mathrm{C}$ \\
$\lambda, \mathrm{h}$ & Thermal conductivity, convective heat transfer coefficient \\
$\mathrm{L}$ & heat of vaporization of water \\
$\mathrm{T}$ & Time \\
\hline
\end{tabular}

\section{Model Preparation}

\subsection{Bathtub}

\section{-The Shape/Volume}

In our model, we choose the common bathtub are usually rectangular.

$>$ Length: $1200 \mathrm{~mm}, 1300 \mathrm{~mm}, 1400 \mathrm{~mm}, 1500 \mathrm{~mm}, 1600 \mathrm{~mm}, 1700 \mathrm{~mm}$.

$>$ Width: 700 900mm.

$>$ Height: 355 700mm.

\section{- The Material}

The material conclude: enamel cast iron, enamel steel, FRP(Fiber Reinforced Plastics), artificial agate and artificial marble, terrazzo, wooden, ceramics, and so on. The most common are enamel cast iron, enamel steel and FRP.

\subsection{Temperature}

\section{-Body Temperature:}

When in a healthy state, body temperature is generally relatively constant, that is kept at $37^{\circ} \mathrm{C}$ up and down( roughly between $36.2^{\circ} \mathrm{C}$ and $37.2^{\circ} \mathrm{C}$ ) and doesn't change much external environment. So, we can regard it as $37^{\circ} \mathrm{C}$ when developing the model.

\section{-Water Temperature}

People will feel comfortable when the bath water is at $37 \pm 3^{\circ} \mathrm{C}$ ( approaching the body temperature ).

\section{-Bathroom Temperature}

The room temperature is usually about $20^{\circ} \mathrm{C}$. In our model, we can test different temperature to test the model's accuracy.

\subsection{Convective Heat Transfer Coefficient}

The main factors of influence on the strength of convective heat transfer are: (1) Causes of 
convective motion and flow conditions;

(2) The physical properties of the fluid (depending on the kind, temperature and pressure changes);

(3) The shape of the heat transfer surface, size and relative position; (4) The fluid phase change's exist or not;

Under different circumstances, the intensity of the heat transfer occurs exponentially until a thousand times change, so a convective heat transfer is affected by many factors and the amplitude of the intensity change is much more complex process.

There are some convective heat transfer coefficient experience data ${ }^{[1]:}$

Table 2:Some Convective Heat Transfer Coefficient Experience Data

\begin{tabular}{ll}
\hline \multicolumn{2}{c}{ Some Convective Heat Transfer Coefficient Experience Data } \\
\hline Air natural convection & $5 \sim 25$ \\
Water natural convection & $200 \sim 1000$ \\
Air forced convection & $20 \sim 100$ \\
Water forced convection & $1000 \sim 15000$ \\
\hline
\end{tabular}

\subsection{Enthalpy}

- water

Table 4: Part of the enthalpy of the water table

\begin{tabular}{lc}
\hline & Part of the enthalpy of the water table \\
\hline Temperature $\left({ }^{\circ} \mathrm{C}\right)$ & enthalpy $(\mathrm{kJ} / \mathrm{kg})$ \\
10 & 42.04 \\
20 & 83.91 \\
30 & 125.7 \\
40 & 167.5 \\
50 & 209.3 \\
60 & 251.1 \\
70 & 293 \\
80 & 355 \\
90 & 377 \\
\hline
\end{tabular}

We fit these data, and get the function relationship between the temperature and the enthalpy :

$$
\mathrm{T}=\{10,20,30,40,50,60,70,80,90\}
$$

$$
\begin{array}{r}
h_{w}=\{42.04,83.91,125.7,167.5,209.3,251.1,293,355,377\} \\
h_{w}=4.28551666666667 T-2.65916666666659
\end{array}
$$

\section{-Air}

The air enthapy calculation formula:

$$
\mathrm{h}_{\mathrm{a}}=1.01 \mathrm{~T}+(\mathrm{L}+1.84 \mathrm{~T}) \mathrm{d}
$$

$\mathrm{T}$ is the air temperature, unit: ${ }^{\circ} \mathrm{C} ; 1.01$ is the average constant pressure specific heat capacity of the dry air ,unit: $\mathrm{kJ}(\mathrm{kg} \cdot \mathrm{K})$; 1.84is the average constant pressure specific heat capacity of the steam, unit: $\mathrm{kJ}(\mathrm{kg} \cdot \mathrm{K}) \mathrm{L}$ is the heat of vaporization of water at $0^{\circ} \mathrm{C}$. which is constant $2500 \mathrm{~kJ} / \mathrm{kg}$. 


\section{Models}

\subsection{Formulas and the Process}

\subsubsection{The Formula of Heat Flow(Except the bathtub wall )[4]}

(1) Convection

Unit time, through the water surface dS1, the heat from water to air dQa:

$$
Q_{a}=h \Delta T S_{1}
$$

$h$ is the convective heat transfer coefficient(See Table 4), unit: $W\left(m^{2} \cdot{ }^{\circ} \mathrm{C}\right) \Delta T(\mathrm{~T}-\theta)$ is the temperature difference between the water and air, unit: ${ }^{\circ} \mathrm{C} ; S_{1}$ is the contact area, unit: $\mathrm{m}^{2}$.

(2) Evaporation

Unit time, through the water surface $\mathrm{dS}_{1}$, the heat flow in the evaporation:

$$
\mathrm{Q}_{\mathrm{b}}=\beta\left(p^{\prime \prime}{ }_{\mathrm{v}}-p_{\mathrm{v}}\right) \mathrm{S}_{1}
$$

$\beta$ is the evaporation coefficient (See Ch5.1.3), unit: $\quad W \mathbf{l}\left(\mathrm{m}^{2} \cdot \mathrm{h} \mathrm{Pa}\right) ; p_{y}$ is the steam pressure in the water saturated layer, unit: $\mathrm{Pa} ; p_{v}$ is the steam partial pressure, unit: $\mathrm{Pa} ; S_{1}$ is the contact area, unit: $m$.

(3) Radiation

Radiation heat flow can be calculated by this formula:

$$
Q_{0_{2}}=Q_{c}=\varepsilon(T+273) S_{1}
$$

$\varepsilon$ is the black level which can be 0.97: $\sigma$ is the constant $5.6 \times 10^{-8}$ unit: $W\left(m^{2} \cdot K^{4}\right) ; \quad S_{1}$ is the water surface area, unit: $m^{2}: \mathrm{T}$ is the water temperature, unit: ${ }^{\circ} \mathrm{C}$.

Therefore, the whole heat loss is:

$$
Q=Q_{a}+Q_{b}+Q_{c}=\left[\alpha(T-\theta)+\beta\left(p^{\prime \prime}-p_{*}\right)+\varepsilon(T+273)^{4}\right] S_{1}
$$

\subsubsection{Surface Enthalpy Difference Formula}

In our model, we combine the first two of Formula 6, which are the convection between the water and air and the evaporation. And we can describe the new one with enthalpy.

There is the derivation:

$$
Q_{01}=Q_{a^{4}}+Q_{b^{4}}=\left[\alpha(T-\theta)+\beta\left(p^{\prime \prime}{ }_{y} p_{y}\right)\right] S_{(7)}
$$

According to the Bowen ${ }^{[5]}$ ratio:

$$
\frac{\alpha}{\beta}=h=\frac{P_{a} C_{p}}{0.623 L}
$$

$\mathrm{P}_{\mathrm{a}}$ is the atmospheric pressure, unit: $\mathrm{hPa} ; \mathrm{C}_{\mathrm{p}}$ is the air specific heat capacity $1.005 \mathrm{~kJ} \mathrm{~kg} \cdot{ }^{\circ} \mathrm{C}$; L is the heat of vaporization of water which is constant $2500 \mathrm{~kJ} / \mathrm{kg}$. According to the Formula 7: 


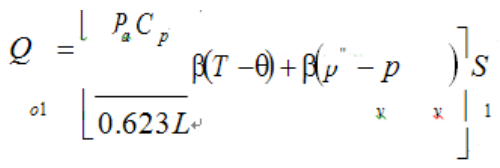

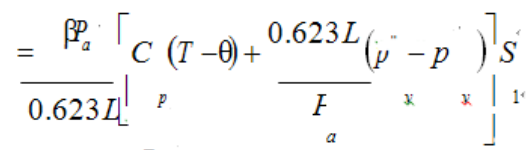

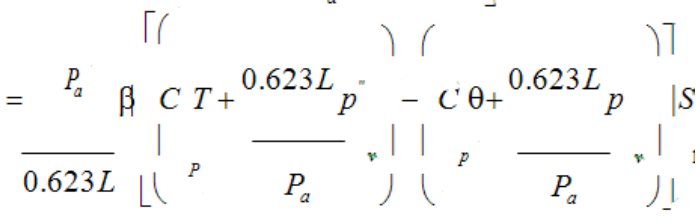

$$
\begin{aligned}
& =\frac{P_{a}}{0.623 L} \beta\left[h_{\tau}-h_{g}\right] S_{1}
\end{aligned}
$$

hT the enthalpy of the water at $t^{\circ} \mathrm{C}$, unit: $\mathrm{kJ} / \mathrm{kg}$; h $\quad$ sthie ehthalpy of the air at $\theta^{\circ} \mathrm{C}$ (Formula 2 ), unit: $\mathrm{kJ} / \mathrm{kg}$.

The Formula 9 is applied in our model which conclude the the convection between the water and air and the evaporation.

\subsubsection{Evaporation Coefficient}

The general formula[6]:

$$
\beta=\left[22.0+12.5 W^{2}+2.0(T-\theta)\right]^{1 / 2}
$$

$\mathrm{W}$ is the bathroom indoor wind speed, unit: $\mathrm{m} / \mathrm{s}$; the others are the same as before.

\subsubsection{The Thermal Loss From the Bathtub Wall[2]}

(1) The heat conduction inside the bathtub wall: Thermal loss is :

$$
\Phi=\lambda S \frac{\Delta T}{{ }^{2} M}
$$

$h_{w}$ is the convective heat transfer coefficient of water(See Table 4), unit: $W\left(m^{2} \cdot K\right) ; \mathrm{S}_{2}$ is the bathtub beside area, unit: $\mathrm{m}^{2}$; the others are the same as hefore

(3) The convection between the bathtub wall and the air:

Heat flow is:

$$
\Phi_{3}=h_{a} S_{4} \Delta T
$$

$h_{\alpha}$ is the convective heat transfer coefficient of air(See Table 4$)$, unit: $W \mathbf{Y}\left(m^{2}, K\right)$;

$\mathrm{S}_{3}$ is the bathtub beside area, unit: $\mathrm{m}^{2}$; the others are the same as before.

Therefore, the whole thermal loss is:

$$
Q_{03}=\Phi_{1}+\Phi_{2}+\Phi_{3}
$$

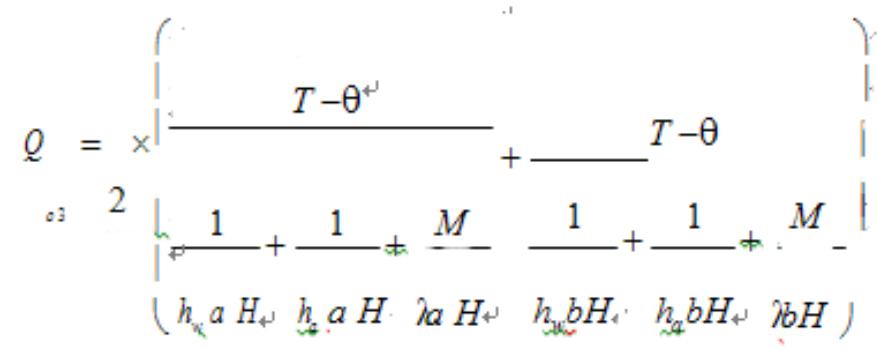




\subsubsection{The Whole Thermal Loss}

Therefore, the whole heat flow:

$O_{\Omega}=Q_{O 1}+Q_{O_{2}}+Q_{O 3}$

$$
Q_{\Omega}=f(a, b, H, T, \theta, \lambda, M)
$$

Qo1 is the heat flow during the convection between the water and air and the evaporation, unit: W: $\mathrm{O}_{02}$ is the heat flow in the radiation, unit: $\mathrm{W} ; \mathrm{Q}_{03}$ is the heat floe through the bathtub wall, unit: W.

We can get a formula:

$$
c m d T=-d \underline{Q}_{n-1}
$$

$c$ is the specific heat capacity of water(Formula 1), unit: $\mathrm{kJ} /\left(\mathrm{kg} \cdot{ }^{\circ} \mathrm{C}\right) ; \mathrm{m}$ is the weight of water in the bathtub, unit: $\mathrm{kg}$; $\mathrm{dT}$ is the increment of the water temperature. If we set the initial water temperature as $39^{\circ} \mathrm{C}$ (See $\mathrm{Ch} 4.2$ ). We can get the numerical solution by using the difference equation:

$$
c m\left(T-T_{i+1}^{i}\right)=Q_{0.1}^{+}=f\left|\left(a, b, H, \frac{T+T}{2}, \theta, i, M\right)\right|
$$

Fit the numerical with the least squares.we can get the equation:

$T=-0.000535115010390992 t+38.9894676181136$

Then we get the curve of the temperature and the time

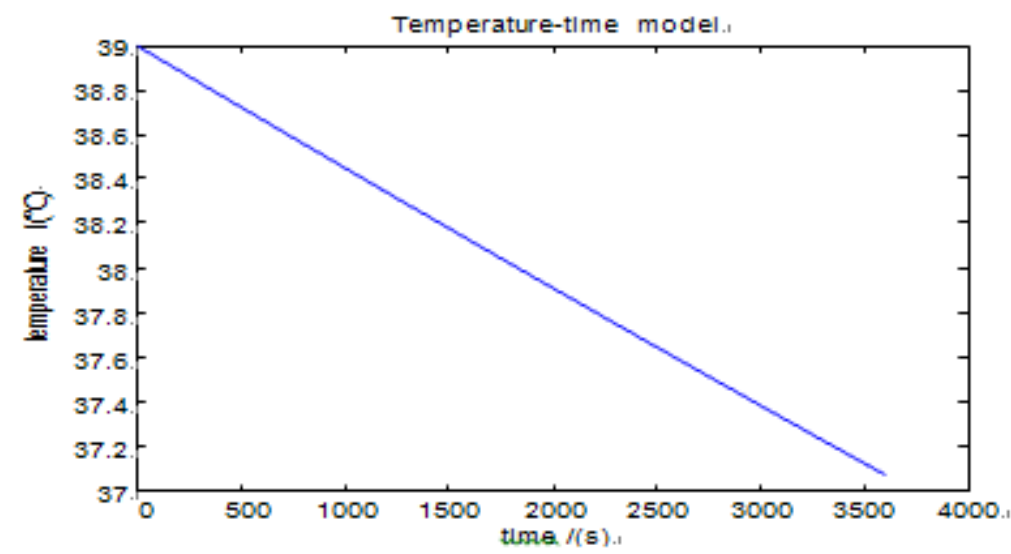

Figure 1, The relation between the time and the bathtub water temperature

From Figure 1, we can see that the bathtub water temperature is reducing by the time. 


\subsubsection{The Thermal Supply}

The supply heat flow:

$$
O_{i}=c \Phi_{1}, \Delta T
$$

$c$ is the specific heat capacity of water(Formula 1$)$, unit: $\mathrm{kJ} /\left(\mathrm{kg} \cdot{ }^{\circ} \mathrm{C}\right) ; \mathrm{q}_{\mathrm{*}}$ is the the water volume in unit time, unit: $\mathrm{ml} / \mathrm{s} ; \Delta T$ is the temperature between the bathroom water and the hot water.

If we want to keep the temperature, we must ensure the supply equals the loss:

$$
O_{n}=Q_{1}
$$

The hot water's addition will change the water's height and change the contact area, so, the thermal loss may be changed. According to our model, we set the initial temperature at $38^{\circ} \mathrm{C}$ and the added water $65^{\circ} \mathrm{C}$ to observe the change of the water weight during the addition and get the figure.

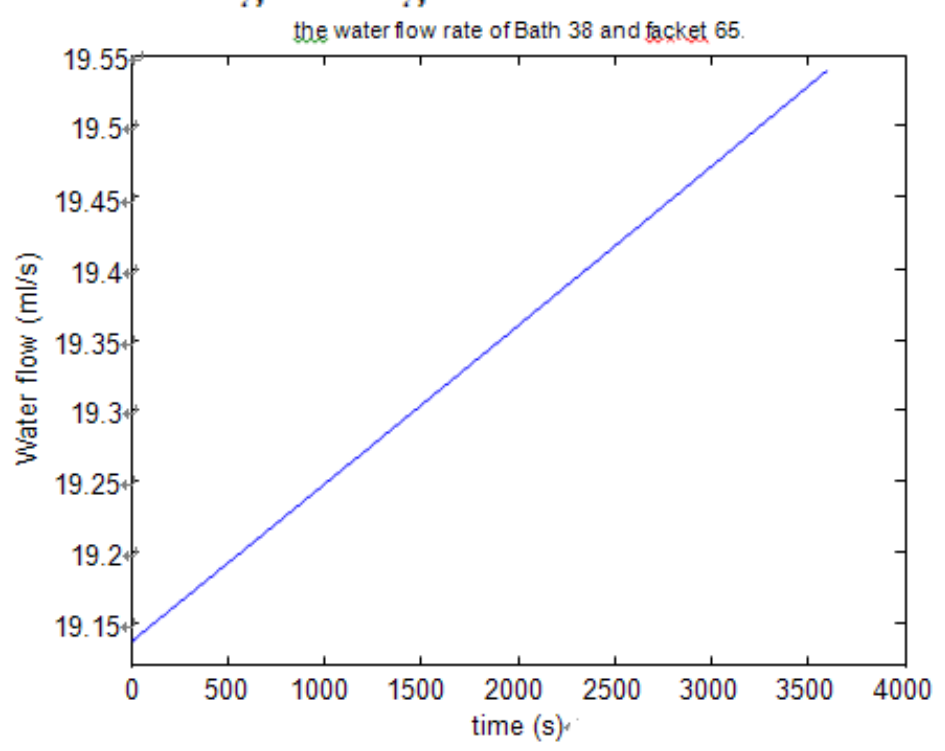

Figure 2, Change of water flow with the time

From Figure 2 ,we can see that the water floe's increment is a little which almost doesn't make any influence. So we can ignore this weight, assume the weight doesn't change during adding water.

\subsection{Model}

From Formula 17, we can see that many factors can change the result, we just can't discuss all these factor change together. So,we can make some of them constant to discuss the others' result to our result.

At first ,we can make the shape of the bathtub is constant which length, width, height are $1.7 \mathrm{~m}$, $0.8 \mathrm{~m}, 0.7 \mathrm{~m}$ ( See Ch4.1), and we change the temperature of the water to observe the added water flow;s change.(See Ch 5.2.1) We get the Figure 3.

Second, we can make the temperature constant, the bathtub at $35{ }^{\circ} \mathrm{C}$, hot water at70 ${ }^{\circ} \mathrm{C}$.Also, we make the volume constant $\left(1.7^{*} 0.8^{*} 0.7\right)$. Then we can change thelength and the height to observe the result to discuss the shape influence. We get the Figure 4.

Third, if we add the bubble bath additive. It will reduce the evaporation because of the space layer formed by the bubble, between the water and the air. So, we reduce the evaporation and get the Figure 5. Fourth, we discussed the influence caused by the person. Through our calculation,we find the influence to the convection is a little almost can be ignored and the most 
important is the person's motion, which can speed up evaporate and increase the heat flow, so we just need more hot water to keep the temperature.We set the bathtub temperature at $38^{\circ} \mathrm{C}$ and discuss the two condition. We get the Figure 6.

Considering the complexity of the space heat conduction equation, we just consider the solution of the one-dimensional space heat conduction equation. We just consider the spread of the temperature with the bathtub depth. Build the model temperature with the depth in space and time with the difference equation. Select any point in the depth, and we set the water temperature at $35^{\circ} \mathrm{C}$, the thermal Conductivity as 0.59.We get the figure with MATLAB:

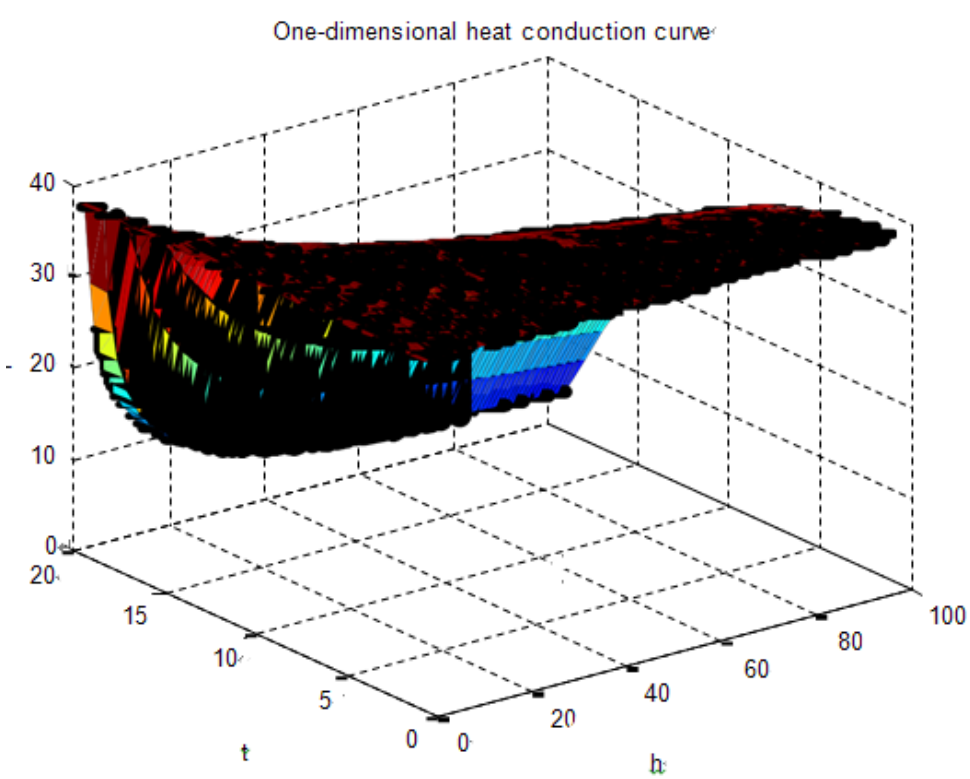

Figure 3, One-dimensional heat conduction curve

\subsubsection{The Temperature of Water}

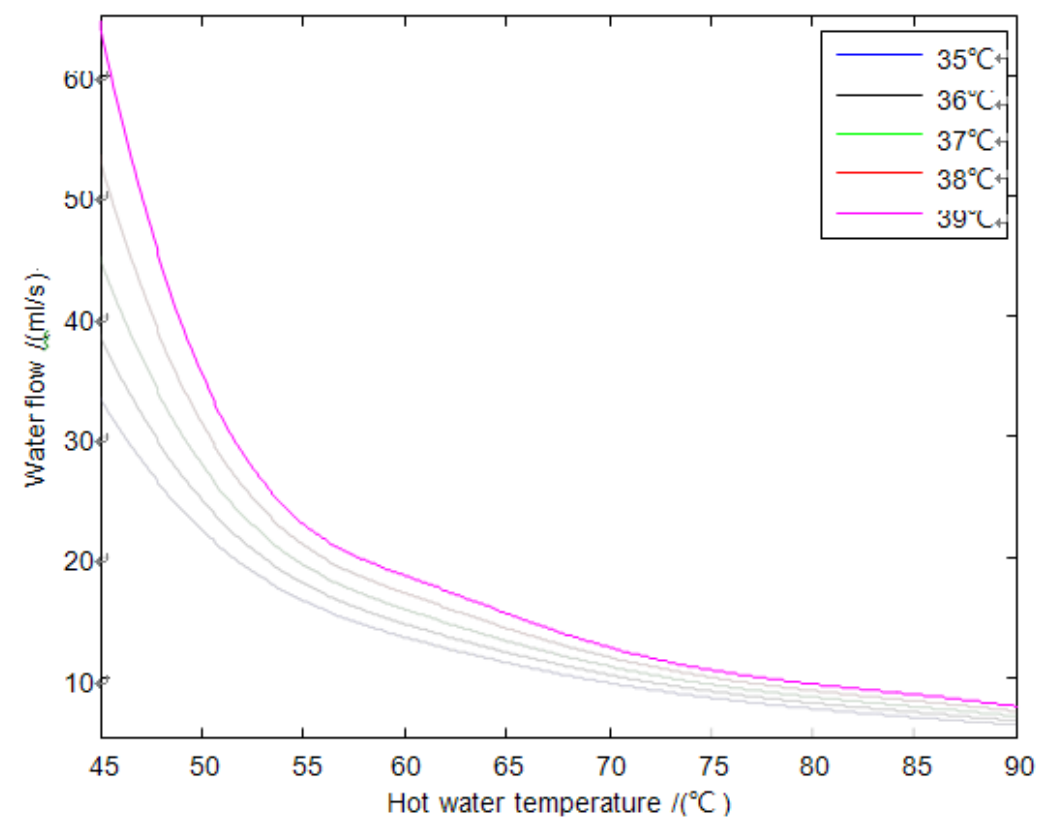

Figure 4, The added water flow's change with the temperature The colorful lines describe the different bathtub water temperature.

From Figure 3, we can see the hot water temperature is higher, the bathtub's lower, we can save more water. But we also should determined the temperature according to our own condition to find a most comfortable way. 


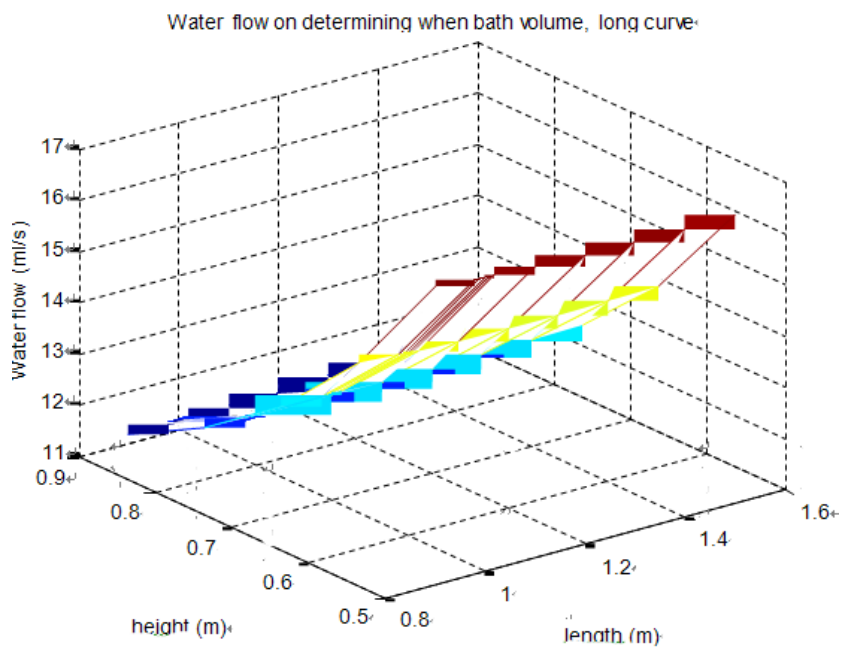

Figure 5, the water flow determined by the bathtub shape Table 5, The water flow determined by the bathtub shape

\begin{tabular}{|c|c|c|c|c|c|c|c|c|c|c|c|}
\hline \multicolumn{12}{|c|}{ The water flow determined by the bathtub shape } \\
\hline & 0.9 & 0.98 & 0.99 & 1.00 & 1.01 & 1.02 & 1.1 & 1.2 & 1.3 & 1.4 & 1.5 \\
\hline 0.5 & 16.760 & 16.677 & 16.669 & 16.660 & 16.652 & 6.645 & 16.59 & 16.5 & 16.535 & 16.531 & 16.539 \\
\hline 0.6 & 14.579 & 14.510 & 14.503 & 14.497 & 14.491 & 14.485 & 14.44 & +14.4 & 14.426 & 14.440 & 14.466 \\
\hline 0.7 & 13.067 & 13.013 & 13.008 & 13.003 & 12.999 & 12.995. & 12.97 & 12.9 & 12.986 & 13.017 & 13.062 \\
\hline 0.8 & 11.974 & 11.934 & +11.930 & 11.927 & 11.925 & $\$ 1.923$ & 11.91 & 11.9 & 11.964 & 12.014 & 12.076 \\
\hline 0.9 & 11.159 & 9. 11.133 & 11.132 & 11.131 & 11.130 & 11.129. & 11.13 & 11.1 & 11.221 & 11.289 & 11.369 \\
\hline
\end{tabular}

The figure includes too many data and we can not get the intuitive result, so we pick out some point data in a specific range. And from the table ,we can find a best condition, the length is 1.02,the height is 0.9 . At this point,the width is 1.04 and the bottom is nearly a square. But the bathtub can't be too high, so the relatively proper shape is that height is 0.7 , the length is 1.2 , the width is 1.3 ,nearly a square as well.

As we know, when the area is constant,the circle's perimeter is shortest,so we can infer the optimal bathtub is a circle-bottom.

At this condition, the height is 0.7 ,the radius is 0.6580 , the water flow is 12.3003 . So it saved the most water and is the optimal method. 


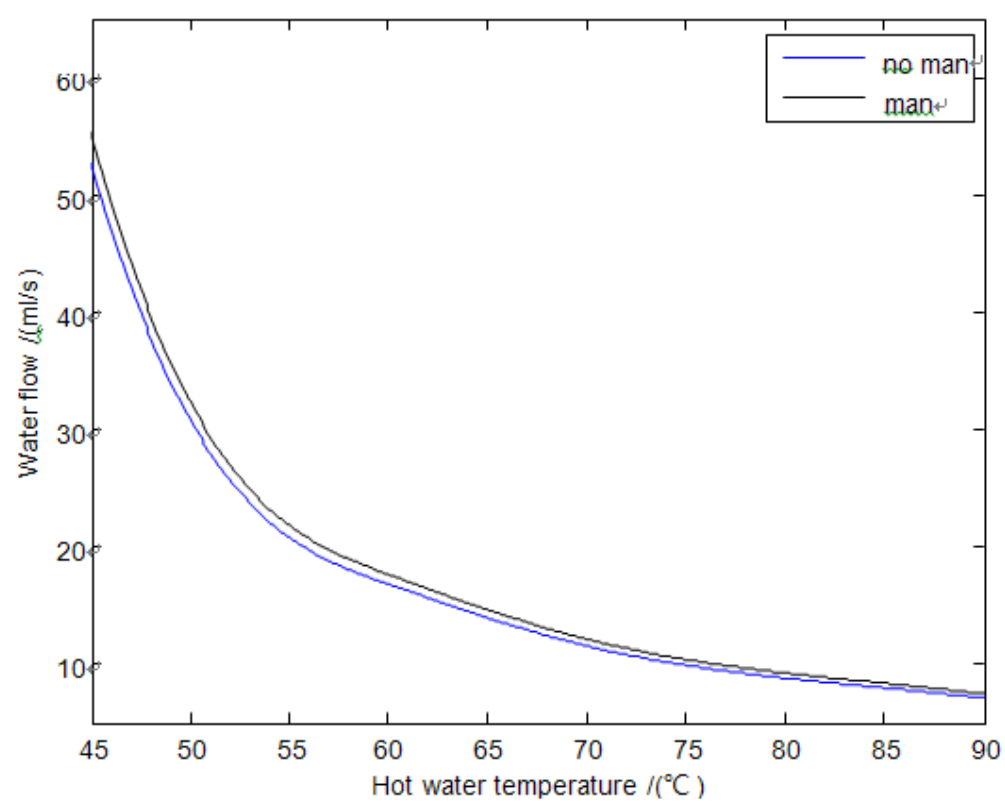

Figure 6, The comparison the person in he bathtub or not

From the figure, we can see the person will speed up the thermal loss and we need more hot water to keep the temperature.

\subsubsection{Bubble Bath Additive}

Use our model to compare the two conduction before and after the bubble bath additive added.We get the Figure 5 .
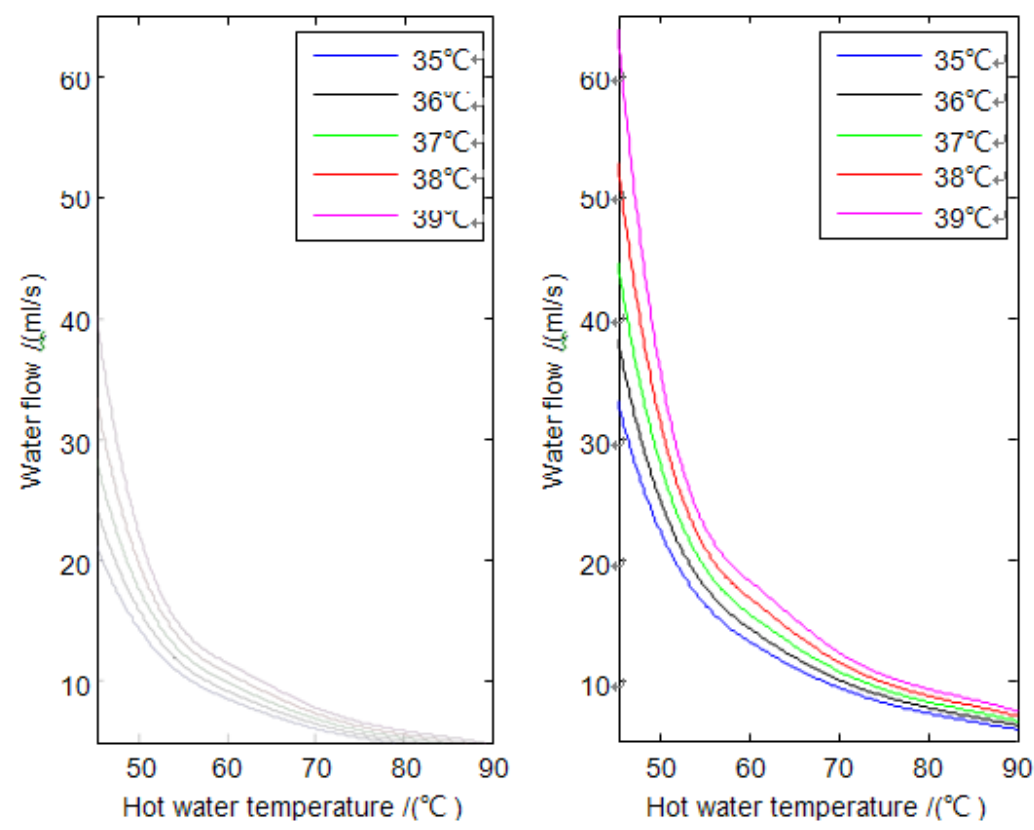

Figure 7, The comparison before and after the bubble added

The left one is the bubble bath additive and the right one is the same as before.

From the figure ,we can see that the bubble bath additive can reduce the thermal loss. And we all know, it can assist to clean. So, it'll be really good if we add it during bathing.

\subsection{Conclusion}

$>$ According to the model, we find the optimal strategy which can keep the temperature even throughout the bathtub and as close as possible to the initial tem perature without wasting too much water.

$>$ We can choose the different temperature of the bathtub water and the added hot water, and we can see the different water flow of the hot water from Table 6.

After calculating, it can be observed that the water will not exceed the capacity. 
To avoiding wasting water, we should not use too much water. So we can make the bathtub volume constant. At this case, the optimal shape is the circle-bottom bathtub.

$>$ The model can also be used to many other conditions about the heat flow of water, such as, one can calculate the heat loss of the river surface to analyze the environment around the river.

\section{Model Evaluate and Improvement}

\section{(1) Strength}

\section{- Rationality:}

Our model is proved to reasonable by the testing, we can use it during washing to get a comfortable condition and save as possible as more water.

\section{- Intuitive:}

With the assistant of the tables and the figures, the result of our model is very intuitive and easy to understand.Everyone can get a comfortable condition to keep the temperature close as possible as to the initial temperature.

\section{- Accuracy:}

We take almost all the factors into consideration during the model developing, and we discussed the enough range of the actual situation. It can be thought very accurate with a high accuracy.

\section{- Universality:}

Our model can also be applied in many other cases except the case mentioned in the problem because our formula can be used to calculate many other things of the heat loss of the water. For example, we can calculate the heat loss of the river surface to analyze the environment around the river.

\section{(2)weakness}

What we modeled in space is not perfect as expected because we didn't get a perfect three-dimensional figure.So we use more two-dimensional figures to make up the weakness.

\section{(3)Improvement}

If possible, we can build a model to describe the temperature of the bathtub water in space, which can prove our result more effectively.

\section{Write for Users}

We always meet the unhappy case: the bathtub water will get noticeably cooler after a while during washing. That's because of the heat loss which can't be avoided. Well, there some spa-style bathtub to assist to keep the temperature, but not all of us ca afford it, we have to use the common one.

The unavoidable heat loss can caused by many factors, such as, the water evaporation, the radiation,the heat conduction and some complex factors.

We find the optimal solution by our model and describe it by the tables.And you can determine your faucet water flow by checking out the tables.

(1)If one already has a bathtub and doesn't want to change it. There is the most common one whose length, width, height is $1.7 \mathrm{~m}, 0.8 \mathrm{~m}, 0.7 \mathrm{~m}$. And one can know the water flow by checking the Table 6 . If the bathtub is in other shapes, one can also check the Table 7. 
Table6 The water flow determined by the faucet temperature and the bathtub

\begin{tabular}{|c|c|c|c|c|c|c|c|c|c|c|c|c|}
\hline \multirow[b]{3}{*}{ Bubble } & \multicolumn{12}{|c|}{ The water flow determined by the faucet temperature and the bathtub } \\
\hline & \multicolumn{2}{|c|}{45} & \multicolumn{2}{|c|}{50} & \multicolumn{2}{|c|}{60} & \multicolumn{2}{|c|}{70} & \multicolumn{2}{|c|}{80} & \multicolumn{2}{|c|}{90} \\
\hline & Y & N & Y & N & Y & N & Y & N & Y & N & Y & $N+$ \\
\hline 354 & 21.3 & 33.1 & 14.2 & 22.1 & 8.5 & 13.2 & 6.1 & 9.5 & 4.7 & $7.4+$ & 3.9 & 6.0 \\
\hline 364 & 24.5 & 38.2 & 15.7 & 24.6 & 9.2 & 14.3 & 6.5 & 10.1 & 5.0 & 7.8 & 4.1 & 6.4 \\
\hline 374 & 28.4 & 44.6 & 17.5 & 27.4 & 9.9 & 15.5 & 6.9. & 10.8 & 5.34 & 8.3 & 4.3 & 6.7 \\
\hline $38+$ & 33.5 & 52.9 & 19.5 & 30.8 & 10.7 & 16.8 & 7.3 & 11.6 & 5.6 & 8.8 & 4.5 & 7.1 \\
\hline $39_{*}$ & 40.3 & 63.9 & 22.0 & 34.9 & 11.5 & 18.3 & 7.8 & 12.4 & 5.9 & 9.4 & 4.7 & 7.5 \\
\hline
\end{tabular}

In Table 6, $\mathrm{W}$ is the water flow of the faucet, $\mathrm{T} 1$ is the temperature of the hot water, $\mathrm{T} 2$ is the temperature of the bathtub. ' $\mathrm{Y}$ ' is the way of adding the bubble bath additive, ' $\mathrm{N}$ ' is not.

One can choose different temperature, but the suggestion is: the relatively comfortable condition is $\mathrm{T} 1$ at $70^{\circ} \mathrm{C}$ and the $\mathrm{T} 2$ at $35^{\circ} \mathrm{C}$

Table 7, The water flow determined by the bathtub

\begin{tabular}{|c|c|c|c|c|c|c|c|c|c|c|c|}
\hline \multicolumn{12}{|c|}{ The water flow determined by the bathtub shape } \\
\hline 2 & 0.90 & 0.98 & 0.99 & 1.00 & 1.01 & 1.02 & 1.1 & 1.2 & 1.3 & 1.4 & $1.5^{\prime}$ \\
\hline $\begin{array}{l}0.5 \\
16.539\end{array}$ & 16.760 & 16.677 & 16.669 & 16.660 & 16.652 & 16.645 & 16.595 & 16.555 & 16.535 & 16.531 & \\
\hline $\begin{array}{l}0.6 \\
14.466\end{array}$ & 14.579 & 14.510 & 14.503 & 14.497 & 14.491 & 14.485 & 14.449 & 14.428 & 14.426 & 14.440 & \\
\hline $\begin{array}{l}0.7 \\
13.062\end{array}$ & 13.067 & 13.013 & 13.008 & 13.003 & 12.999 & 12.995 & 12.973 & 12.970 & 12.986 & 13.017 & \\
\hline $\begin{array}{l}0.8 \\
12.076\end{array}$ & 11974 & 11.934 & 11.930 & 11.927 & 11.925 & 11.923 & 11.916 & 11.930 & 11.964 & 12.014 & \\
\hline $\begin{array}{l}0.9 \\
11.369\end{array}$ & 11.159 & 11.133 & 11.132 & 11.131 & 11.130 & 11.129 & 11.137 & 11.16 & 11.221 & 11.289 & \\
\hline
\end{tabular}

Table7 describes the condition whose bathtub temperature is $35^{\circ} \mathrm{C}$ and the faucet temperature is $70^{\circ} \mathrm{C}$, which is the optimal condition determined by our model.

(2)If someone wants to change the bathtub, the suggestion is: the circle-bottom bathtub is the best choice.

\section{Conclusion}

The bathtub water will get cooler during washing because of the heat loss, so we have to add the hot water to make up the loss and reheat the water. However, the bathtub capacity is limited, so the water will overflow when exceeding the capacity. In order to solve this problem, we developed a model of the bathtub temperature in space and time to determine the optimal strategy which can keep temperature without wasting too much water.Then,we determine the extent to the relevant factors our strategy depends upon. 
At the beginning, we should develop the model according to the law of energy conservation. First, we calculate the whole heat loss which concludes the heat flow caused by the radiation, on the water surface, and in the cycle of water-bathtub-air. In this step, we use the enthalpy difference formula, heat radiation formula and the Fourier Heat Conduction Law. Second, according to $Q=c m \Delta t$, one can get the numerical solutions of the temperature change with the time by the difference equation.The equation of the temperature and the time can be obtained by fitting these solutions. Third, after discreting the space heat conduction equation, one can get the numerical solution of the space temperature field of the bathtub.

Then, we study the relationship between each two of water supply, the bathtub temperature, the water temperature, the bathtub shape and heat loss on the surface. With the law of the energy conservation, we get the standard between the bath water and the faucet water and make a table for the users(Table 6). We can get the optimal strategy by analyzing the bathtub shape with the method of optimizing the single factor. The optimal one is the circle-bottom bathtub. The conclusion has been gotten: the bubble bath additive will reduce the heat loss by reduce the evaporation coefficient and the person's motion will increase the heat loss by speed up the water movement.

In the end, this problem had been solved well by our model which can help us to judge the hot water flow based on our own choice with the model's rationality, intuitive, accuracy and universality.

\section{Reference}

[1]Chaohong He,Xiao Feng. Principles of chemical engineerin. Beijing: Science Press, (4)190:1-12,2002.

[2]Guosheng Dai. Heat Transmission science . The second edition.Higher EducationPress, Sep 8th,1998.

[3]Jie Su. Process parameters and instrument . The first edition. China Electric PowerPress, Jul 2nd, 2008.

[4]Zhenguo Zhao. The surface heat enthalpy difference formula and its application. Shuili Xuebao.

(2) 72: 1-5,2002.

[5]Bowen L S. The ratio of heat losses by conduction and by evaporation from any water surface.phys.Rev.(27):779-787,1-11,1926

[6]Huiquan Chen, Shimin Mao. The surface of the water evaporation and the coefficient of heat transfer research--The general formula.Beijing:The surface of the water evaporation and coefficient of heat transfer research consortium,Aug ${ }^{\text {th }}, 1991$.

[7]Lihui Wang. Research of Generator Temperature Field on Water Cooling SystemFault.The second edition. China Electric Power Press, Oct 4th, 2008.

[8]Yan Zhang. MATLAB Image Processing Super Learning Manual. The first edition. POST\&TELECOM PRESS, Sep 8th,2014.

[9]Chinese Health News, Sogou encyclopedia, Bubble bath,2002. http://baike.sogou.com/v2508970.htm?fromTitle=\%E6\%B3\%A1\%E6\%B3\%A1\%E

6\%B5\%B4\#para1 